\title{
BMJ Open Clinical effects of high-intensity laser therapy on patients with chronic refractory wounds: a randomised controlled trial
}

\author{
Qian Lu, ${ }^{1}$ Zhifei Yin, ${ }^{2}$ Xuefeng Shen, ${ }^{3}$ Jinhua Li, ${ }^{3}$ Panpan Su, ${ }^{1}$ Min Feng, ${ }^{1}$ \\ Xingjun $\mathrm{Xu}^{2}{ }^{2}$ Weiwei $\mathrm{Li}^{1}{ }^{1}$ Chuan $\mathrm{He},{ }^{1}$ Ying Shen (D) ${ }^{2}$
}

To cite: Lu Q, Yin Z, Shen X, et al. Clinical effects of highintensity laser therapy on patients with chronic refractory wounds: a randomised controlled trial. BMJ Open 2021;11:e045866. doi:10.1136/ bmjopen-2020-045866

- Prepublication history for this paper is available online To view these files, please visit the journal online (http://dx.doi org/10.1136/bmjopen-2020045866).

QL, ZY, XS and JL contributed equally.

QL, ZY, XS and JL are joint first authors.

Received 24 0ctober 2020 Accepted 25 June 2021

Check for updates

(c) Author(s) (or their employer(s)) 2021. Re-use permitted under CC BY-NC. No commercial re-use. See rights and permissions. Published by BMJ.

For numbered affiliations see end of article.

Correspondence to Ying Shen; shenying_1981@hotmail.com and

Chuan He;

he-chuan@outlook.com

\section{ABSTRACT}

Objective To investigate the effectiveness of highintensity laser therapy (HILT) on chronic refractory wounds. Design Randomised controlled trial.

Setting The outpatient wound care department of the Affiliated Jiangsu Shengze Hospital of Nanjing Medical University from August 2019 to June 2020.

Participants Sixty patients were enrolled in this study and were randomised into control $(n=30)$ and treatment $(n=30)$ groups.

Interventions and outcome measures The control group was treated only with conventional wound dressing, whereas the treatment group received irradiation with HILT in addition to standard wound care, such as debridement, wound irrigation with normal saline solution and application of dressing and sterile gauze. Patient scores on the Bates-Jensen Wound Assessment Tool (BWAT) and Pressure Ulcer Scale for Healing (PUSH) were evaluated before and after 1, 2 and 3 weeks of treatment.

Results One patient was excluded from the control group, and a total of 59 subjects completed the trial. The BWAT scores significantly decreased in the treatment group compared with the control group at the end of 3-week treatment (difference $=-3.6 ; 95 \% \mathrm{Cl}-6.3$ to-0.8; $\mathrm{p}<0.01$ ). Similarly, patients in treatment group showed a significant reduction of PUSH scores compared with the control group (difference $=-5.3 ; 95 \% \mathrm{Cl}-8.1$ to $-2.6 ; \mathrm{p}<0.01$ ).

Conclusions The therapeutic effects of HILT on chronic refractory wounds are significant and far more superior to those of conventional wound dressing.

Trial registration number Chinese Clinical Trial Registry; ChiCTR1900023157. URL: http://www.chictr.org.cn/ showproj.aspx?proj=38866

\section{INTRODUCTION}

Chronic refractory wounds refer to wounds that cannot heal with conventional treatments for more than 1-2 months and develop into chronic ulcers, multiple drug-resistant bacterial infection of the incision and subcutaneous fat liquefaction. ${ }^{1}$ Refractory wounds caused by trauma, burns/scalds, pressure injuries, venous leg ulcers, postoperative
Strengths and limitations of this study

- The present study is one of the few studies to use high-intensity laser therapy as a clinical intervention on chronic refractory wounds.

- The cases were selected under strict quality controls to ensure comparable results.

- Due to small number of patients with diabetic wounds and pressure injuries, subgroup analyses of different wound types could not be performed.

- The study included a variety of wounds of different aetiologies, pathologies and locations. This leads to confusion as to the best application of this technology.

infections and diabetic foot ulcers pose a challenge in clinical treatments. ${ }^{2}$ Clinical manifestations of refractory wounds include secondary infection of the surrounding skin, such as skin irritation, congestion, exudation, erosion and ulcers, which can be life threatening. Refractory wounds pose a significant challenge for clinical intervention, resulting in great psychological stress to patients and greatly increasing their sufferings and economic burden. ${ }^{3}$ Traditional phototherapies, such as infrared therapy and low-level laser therapy (LLLT), can effectively heal skin wounds. The biological effects of laser therapy promoted by these therapeutic methods are similar and involve a decrease in the number of inflammatory cells, increased fibroblast proliferation, stimulation of angiogenesis, formation of granulation tissue and increased collagen synthesis. ${ }^{45}$ However, owing to low light energy and long treatment sessions, the effects of LLLT on chronic refractory wounds remain uncertain. ${ }^{6}$

High-intensity laser therapy (HILT) has been used more recently in the basic research and clinical rehabilitation practice, with performance at Watt level (high-intensity 
laser, class 4 laser). ${ }^{7}$ The main difference between HILT and LLLT is that the more powerful beams (power $>500 \mathrm{~mW}$ ) are irradiated to penetrate deeper, bringing a desired high amount of multidirectional energy to deep tissues in a short time. ${ }^{8}$ Similar to the physiological mechanisms of LLLT, HILT can stimulate repairs to the damaged tissues and peripheral nerves, promote blood circulation in the local tissue and accelerate the healing of refractory wounds. Moreover, it can stimulate cells, including pain receptors, in peripheral tissues and the immune system, result in vasodilation, and produce analgesic effects. The primary advantage of HILT over LLLT is that its depth of penetration increases with increased power; therefore, it is able to stimulate the deep tissue in a short period of time. ${ }^{9}$ This new phototherapy technology has been playing an increasingly important role in wound healing in recent years. Ebid and El-Sodany ${ }^{10}$ confirmed that 4 weeks of HILT intervention can significantly improve Visual Analog Scale scores, range of motion and quality of life of patients with postoperative breast cancer; these indicators were significantly better than those of the control group. However, the above report did not observe the conditions of wound healing (such as wound size and depth). Another clinical study also demonstrated the effectiveness of HILT in slow-to-heal caesarean section in women with diabetes. However, the study only compared the wound areas of patients who received HILT or sham HILT (placebo) on the wound surface and did not investigate wound exudation and depth. ${ }^{11}$ Taking these findings into consideration, the purpose of our study was to observe the intervention effects of HILT on wound healing in patients with chronic refractory wounds and to provide clinical evidence for wound repair.

\section{MATERIALS AND METHODS}

\section{Patient and public involvement}

No patients were involved in setting the research question or the outcome measures, nor were they involved in developing plans for or implementation of the study. No patients were asked to advise on interpretation or writing up of results.

\section{Design and participants}

Study design

This study was a prospective, randomised controlled trial to evaluate the efficacy of HILT on wound healing in patients with chronic refractory wounds. Sixty participants were randomly assigned to either the control or treatment group according to simple randomisation.

\section{Participants}

We included patients with refractory wounds who entered an outpatient wound care department at the Affiliated Jiangsu Shengze Hospital of Nanjing Medical University from August 2019 to June 2020.

\section{Inclusion and exclusion criteria}

The inclusion criteria were as follows: (1) aged 30-65 years, male or female, (2) open, full-thickness wounds, such as postoperative wound dehiscence, poorly healing wounds, diabetic foot ulcers, pressure injuries and traumatic wounds, (3) presence of a chronic wound (defined as wounds that fail to heal with conventional treatments for more than 1-2 month), ${ }^{1}$ (4) agreed to participate and signed the informed consent form for clinical research.

The exclusion criteria were as follows: patients with (1) multiple organ failure, (2) systemic metabolic disease and systemic infectious diseases, (3) severe cognitive impairment, language impairment and noncooperation with the treatment, (4) photodermatosis and systemic lupus erythematosus, (5) severe hypertension (systolic blood pressure $>180 \mathrm{~mm} \mathrm{Hg}$, diastolic blood pressure $>120 \mathrm{~mm}$ $\mathrm{Hg}$ ), (6) coagulopathy or recent anticoagulant use, (7) acute malnutrition and (8) those who received immunosuppressive agents, hormones and other drugs affecting wound healing.

\section{Interventions}

\section{Equipment and methods}

1. Control group: all patients were placed in comfortable positions; their skins were fully exposed and they received the same standard wound care, such as debridement, irrigation of the wound with normal saline solution and application of dressing and sterile gauze. The specific operation process was as follows. After the necrotic or hyperkeratotic tissue was debrided with a scalpel, the skin around the wound was disinfected with $0.05 \%$ iodophor and then cleaned with saline. The conventional external medicine used is Bayer Tan silver ionic alginate and foam dressing (Kang Le Bao, China Medical Supplies, Beijing, China). The Mepikang self-adhesive Ag soft silicone foam antibacterial dressing (Moinlycke Health Care, Mikkeli, Finland) was externally applied for ulcers. The skin around the wound was protected using a type II medical gauze $(10 \times 20 \mathrm{~cm}-8 \mathrm{p}$; Xinxiang Huakang Medical Materials, Changyuan, Henan, China) and then fixed with an elastic bandage $(7.5 \times 450 \mathrm{~cm}$; Henan Anbang Weicai Changyuan, Henan, China). The patients were treated once a day, 3 days a week for 3 weeks.

2. Treatment group: on the basis of routine debridement and wound dressing of the control group, HILT was performed before covering the wound. The HILT used in this prospective study was a semiconductive neodymium laser IV with a wavelength of $1064 \mathrm{~nm}$ (BTL6000 , BTL Company, UK), which has been proved to be a class IV laser and has been used in the treatment of pain and wounds. ${ }^{12}$ Laser energy (maximum optical power, $12 \mathrm{~W}$; spot diameter area, $1 \mathrm{~cm}^{2}$; maximum energy density, $150 \mathrm{~J} / \mathrm{cm}^{2}$ ) was applied in a homogenous and standardised manner. The treatment parameters were set as follows: power, $8 \mathrm{~W}$; energy flow density, $80 \mathrm{~J} / \mathrm{cm}^{2}$ and treatment mode, biostimulation mode (continuous stimulation; manually set); irradiation time was determined according to the wound area $\left(\mathrm{cm}^{2}\right)$. The probe was suspended $2 \mathrm{~cm}$ above the wound edge, and the wound area was quickly scanned 
in a horizontal direction. Treatment was performed via a single application of laser therapy once a day, three sessions a week for 3 weeks.

3. The study objectives and potential risks involved were explained to the patient in detail. Informed consent and permission to use wound photographs and case details for publication/research purposes were obtained. Pictures of the wound were taken regularly with a digital camera and the wound area was measured in $\mathrm{mm}^{2}$ by using a wound measuring ruler (Colopolst, China Medical Supplies, Beijing, China).

\section{Outcome measures}

The subjects were all assessed at baseline and at weeks 1 , 2 and 3 after intervention.

\section{Primary outcome}

1. Bates-Jensen Wound Assessment Tool (BWAT) ${ }^{13}$ : BWAT contains 13 wound characteristics: size, visible depth, wound edges, undermining and tunnelling processes, necrotic tissue type and amount, exudate type and amount, surrounding skin discolouration, peripheral tissue oedema, peripheral tissue induration, granulation tissue and epithelialisation. Each characteristic is subjectively rated on a 1-5 scale, with 1 indicating the healthiest attribute and 5 indicating the least healthy attribute of the characteristic. The remaining four characteristics (size, depth, edges and undermining) are rated from 0 to 5 , with 0 indicating 'none present' and scored for wounds that have resolved. The 13-item scores can be summed (with no weighting) for a total score ranging from 9 to 65 (profound tissue degeneration).

\section{Secondary outcome}

2. Pressure Ulcer Scale for Healing Tool $(\mathrm{PUSH})^{14}$ : as a secondary parameter, PUSH (V.3.0) was used to assess wound healing over a 3-week period. At weekly intervals, categorical subscores for surface area (length $\times$ width), amount of exudate (drainage) and type of wound tissue were determined and combined to obtain a total score ranging from 0 (completely healed) to 17 (greatest severity). PUSH is suitable for both pressure injuries and other chronic refractory wounds. Its primary advantages are ease of use and high reliability. ${ }^{15}$

\section{Adverse events}

The possible adverse event of HILT was the light burn of skin for belonging to class IV laser with high light energy, so Fitzpatrick skin type should be used to determine the treatment dosage before intervention. Patients with deep skin colour should control the dose and pay attention to the moving speed of the probe to avoid skin damage.

In general, according to the normal operation process, there would be no adverse events. If there were adverse reactions, we should immediately stop the treatment and apply a cold compress. After 24 hours, the patients should be given infrared and ultraviolet treatment.

Death, cardiovascular events, other life-threatening events and rehospitalisation for events related to the intervention were defined as serious adverse events. All reported adverse events were rated by two doctors who had access to event history and medical history of each patient but were blinded to group allocation. These doctors were not otherwise involved in the study. Severity was rated on a 5-point Likert-type scale ranging from very mild to life threatening, relationship with the intervention was rated on a 3-point Likert-type scale (unlikely, possible and likely). Disagreement on particular events was resolved by discussion. If consensus could not be achieved a third reviewer was consulted who had the casting vote.

\section{Sample size}

The minimal mean difference between different stages of pressure injury, as rated by BWAT, was regarded as minimal clinically important difference, which was 4.65 according to a large-scale multicentre study. ${ }^{13}$ To achieve $90 \%$ power with an alpha error of $5 \%$, a minimal sample size of 40 patients (20 per group) was needed to detect statistical significance for a between-group difference in BWAT (with SDs of 4.98 in control and 3.60 in the intervention group). ${ }^{16}$ Assuming $20 \%$ dropout, the minimal number of enrolled patients was 50 (25 per group).

\section{Randomisation and allocation concealment}

Subjects were allocated into the treatment and control groups following the principle of simple randomisation. Randomisation order was computer generated via Microsoft Excel (Microsoft, Redmond, Washington, USA) and concealed by an independent statistician in sequentially numbered opaque envelopes. The allocation was performed by a researcher blinded to assessment. After passing the screening and signing the informed consent form, participants selected an envelope and reported to the distribution centre, which showed the distribution in random order. The participants underwent interventions according to the procedures outlined in figure 1.

\section{Blinding and informed consent}

In this study, the participants were informed that they would have a $50 \%$ chance of being allocated to receive either of the two treatments: irradiation with HILT and conventional wound dressing in the treatment group or conventional wound dressing in the control group. Due to the nature of the clinical intervention, the participants could not be blinded, but they were required to not disclose their allocation to the assessors. All assessors were blinded to group allocation by the following procedure: once a patient was deemed eligible and had provided informed consent, assessors conducted the baseline assessment. After the baseline assessment was completed, assessors left the study site and allocators on site were informed about group assignment by the central allocation agency. At the end of the trial, the statisticians received two sets of data, but did not know whether they corresponded to the control or treatment groups. 


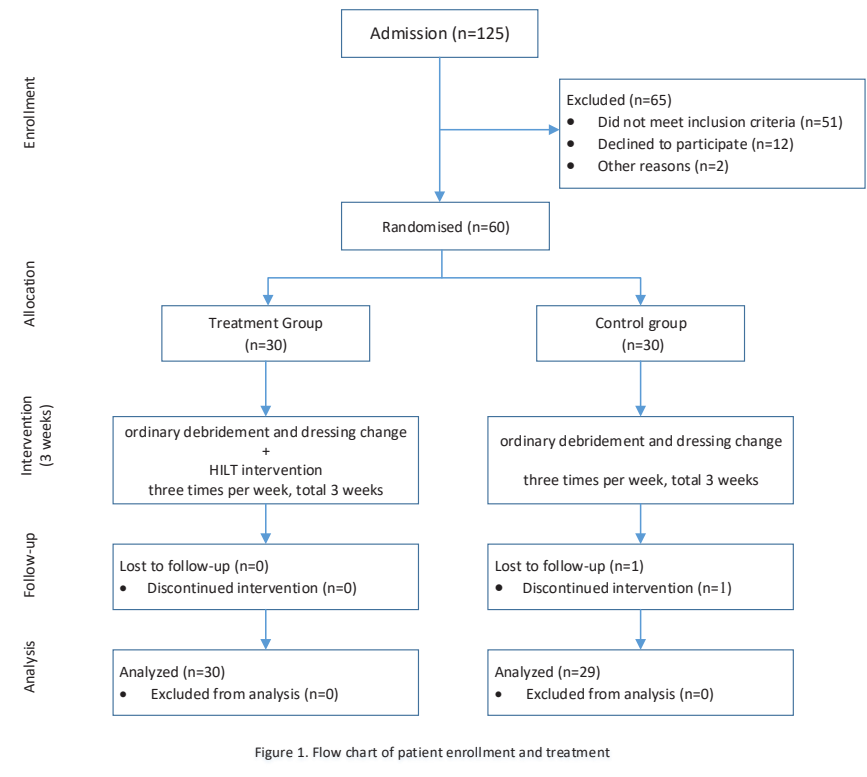

Figure 1 Flowchart of patient enrolment and treatment. HILT, high-intensity laser therapy.

\section{Statistical analysis}

Patient characteristics were summarised using descriptive statistics. Continuous data were summarised using mean and $\mathrm{SD}$ or median and IQR, as appropriate. Categorical data were summarised using frequency and percentage. The BWAT and PUSH scores were analysed using linear mixed-effects modelling for repeated measures over time, with time, group and time by group interaction as the covariates and an unstructured covariance matrix.

Within the mixed model, 95\% CI and $\mathrm{p}$ values were calculated for intergroup contrasts and for changes in the BWAT and PUSH scores within each group over time. A Wilcoxon rank-sum (Mann-Whitney) test was used to compare the difference in categorical subscores for wound size in BWAT and PUSH between different groups at different time points.

\section{Patient involvement}

Patients were not systematically involved in the design of this study. However, conversations with patients and their families on what goals they had helped to design this programme. Moreover, extensive feedback from individual patients allocated to the HILT group was collected during the intervention period each day consultations with therapists in order to better adapted patients' needs and reduce any discomfort during and after treating sessions.

\section{RESULTS}

A total of 60 patients were enrolled in this study. One patient in the control group was excluded because of relocation; as a result, the total number of patients included in the trial was 59. No significant differences were observed in baseline characteristics between the patients in the treatment and control groups (table 1).

\begin{tabular}{|c|c|c|}
\hline Characteristics & $\begin{array}{l}\text { Treatment group } \\
(n=30)\end{array}$ & $\begin{array}{l}\text { Control group } \\
(n=29)\end{array}$ \\
\hline $\begin{array}{l}\text { Age (years), mean } \\
\text { (SD) }\end{array}$ & $49.7(10.8)$ & $48.0(9.6)$ \\
\hline Sex, male (\%) & $22(73 \%)$ & 19 (66\%) \\
\hline $\begin{array}{l}\text { Course of disease } \\
\text { (days), median (IQR) }\end{array}$ & $41.5(34.3,64.8)$ & $40.0(34.0,70.0)$ \\
\hline \multicolumn{3}{|l|}{ Location of wound } \\
\hline Lower limb & $16(54 \%)$ & 15 (52\%) \\
\hline Hand & $3(10 \%)$ & $5(17 \%)$ \\
\hline Ankle or foot & $9(30 \%)$ & $6(21 \%)$ \\
\hline Sacral tail & $1(3 \%)$ & $3(10 \%)$ \\
\hline Lateral hip & $1(3 \%)$ & $0(0 \%)$ \\
\hline \multicolumn{3}{|l|}{ Type of wound } \\
\hline Trauma & $22(73 \%)$ & $19(65 \%)$ \\
\hline Ulcer & $6(20 \%)$ & $8(28 \%)$ \\
\hline Diabetes foot & $2(7 \%)$ & $2(7 \%)$ \\
\hline
\end{tabular}

No patient experienced any pathologic symptoms, such as light burns, during the study period.

\section{BWAT and the PUSH scores}

The BWAT and PUSH results are listed in table 2 and presented in figure 2. The evolution of the wound was also photographed over this period (figures 3 and 4 ). The BWAT scores between the treatment and control groups at baseline were not significantly different $(\mathrm{p}=0.07)$. The BWAT scores significantly improved from baseline to week 3 for both the treatment (difference $=-10.7 ; 95 \%$ CI -12.6 to $-8.8 ; \mathrm{p}<0.01$ ) and control (difference $=-7.1 ; 95 \%$ CI -9.1 to -5.2 ; $\mathrm{p}<0.01)$ groups. However, the improvement in patients in the treatment group was significantly greater than in those in the control group (difference $=-3.6 ; 95 \%$ CI -6.3 to $-0.8 ; \mathrm{p}<0.01$ ).

Similar results were observed for PUSH scores. The PUSH scores between the treatment and control groups at baseline were not significantly different $(p=0.45)$. The PUSH scores significantly improved from baseline to week 3 for both the treatment (difference $=-9.3 ; 95 \%$ CI -11.2 to $-7.4 ; \mathrm{p}<0.01$ ) and control (difference $=-4.0$; $95 \%$ CI -5.9 to $-2.0 ; \mathrm{p}<0.01)$ groups. Furthermore, the improvement in patients in the treatment group was significantly greater than in those in the control group (difference $=-5.3 ; 95 \%$ CI -8.1 to -2.6 ; $\mathrm{p}<0.01$ ).

\section{Categorical subscores for wound size in BWAT and PUSH}

The wound size categorical subscores in BWAT and PUSH are listed in table 3 . The wound size categorical subscore was statistically decreased in treatment group compared with the control group at the end of the third week of treatment $(z=2.792, p<0.01)$. Similar results were observed for PUSH scores. The wound size improvement in patients 

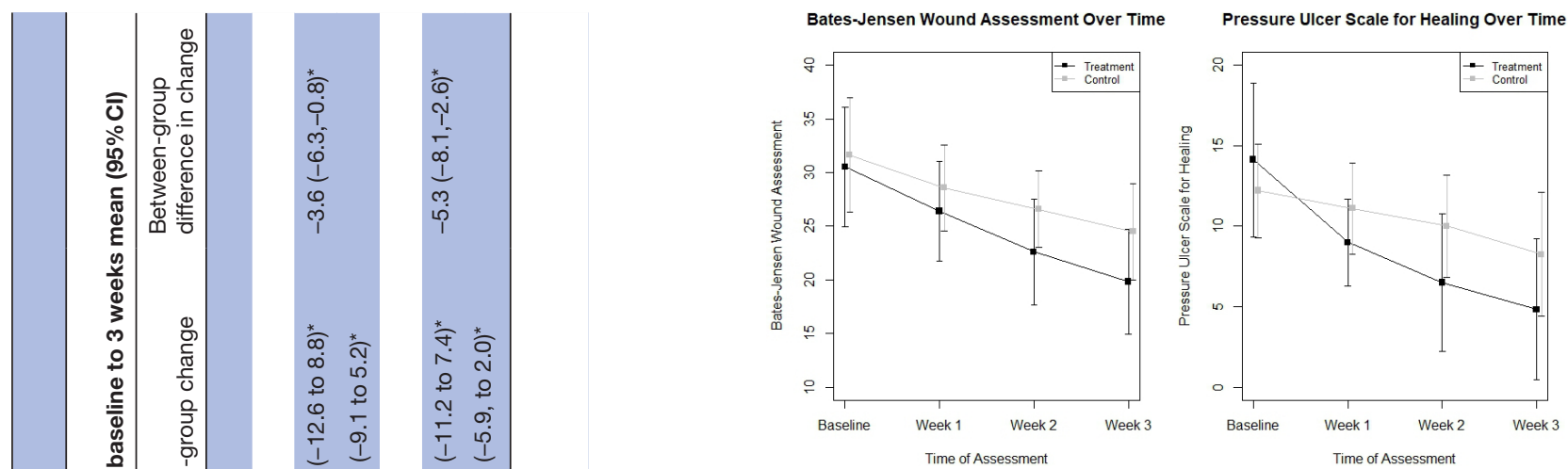

Figure 2 Trajectory of wound and healing characteristics over time.

in the treatment group was significantly greater than in those in the control group $(\mathrm{z}=2.825, \mathrm{p}<0.01)$.

\section{DISCUSSION}

The results of our study demonstrate the significant effects of HILT on wound healing, indicating that HILT is a promising treatment option for chronic refractory wounds. In our study, the BWAT scores of both groups and the PUSH scores of the patients in the treatment group steadily and significantly decreased at weeks 1,2 and 3 compared with those before treatment. Meanwhile, the PUSH scores of the patients in the control group were significantly different only from the second week after the start of treatment compared with the baseline. Furthermore, the BWAT scores in the treatment group were significantly better than those in the control group at weeks 2 and 3, and the PUSH scores were significantly different from those in the control group at weeks 1,2 and 3 .

Wound healing involves coordinated cellular and molecular responses, including immune cell migration, fibroblast proliferation, oxygen and nutrient infusion of new blood vessels and a positive correlation

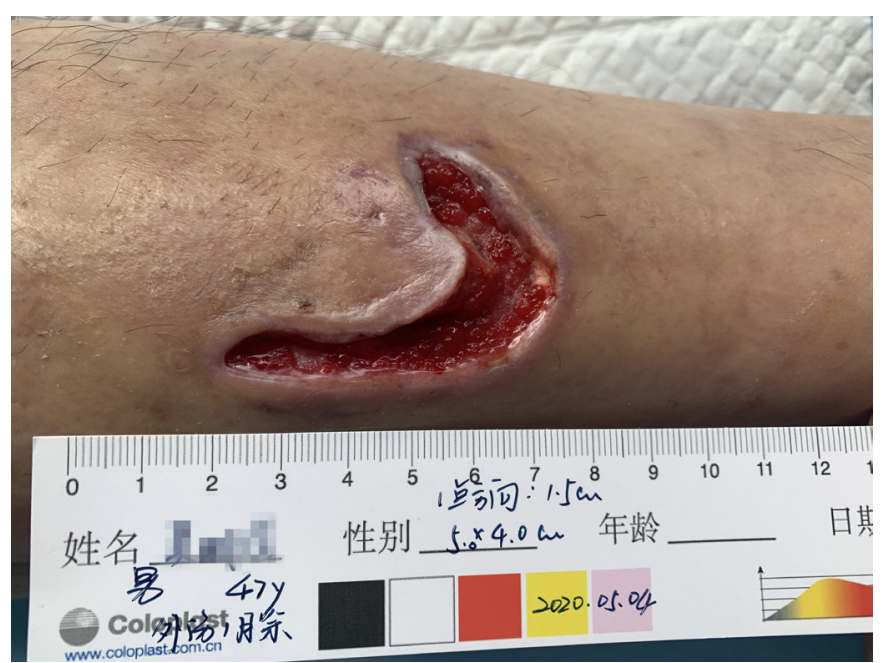

Figure 3 47-year-old male with a trauma wound on lower limb for more than 1 month's duration $(5.0 \times 4.0 \mathrm{~cm})$. 


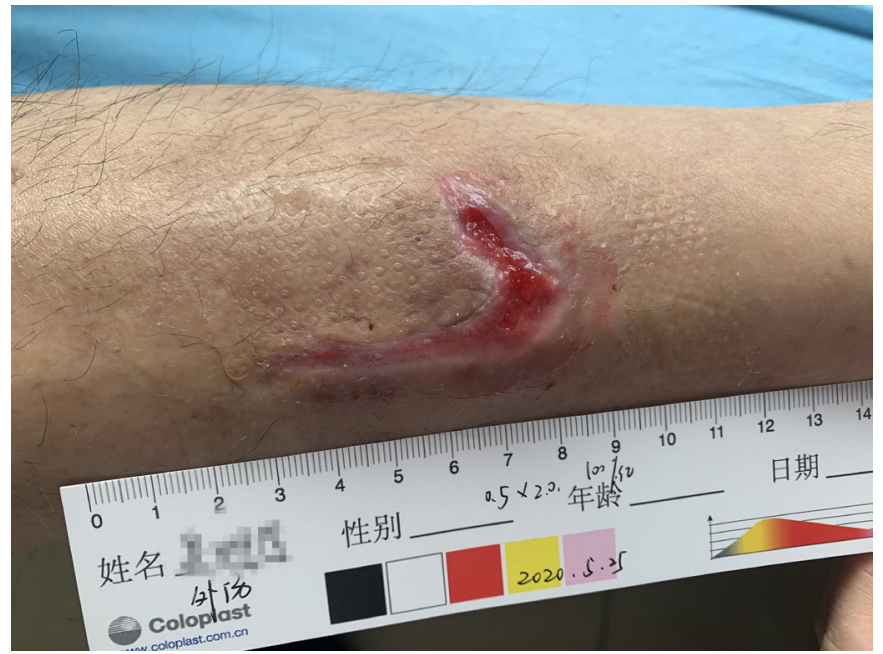

Figure 4 After 3 weeks' HILT treatment combined with standard wound care treatment the wound size had reduced to $0.5 \times 2.0 \mathrm{~cm}$. HILT, high-intensity laser therapy.

with innervation. ${ }^{17}$ The mechanism underlying chronic refractory wounds is complex and has not yet been fully elucidated. Wound treatment, wound dressing and negative-pressure wound therapy are standardised local treatments for chronic refractory wounds. Phototherapy for treating infectious and refractory wounds has attracted great attention as a complementary approach. ${ }^{18}$ HILT has been reported to have anti-inflammatory, analgesic and wound-healing effects, assisting in the management of patients with musculoskeletal disorders. ${ }^{19}$ In addition, HILT can improve local blood circulation, blood vessel permeability and cell metabolism. ${ }^{20}$ Therefore, HILT can aid in the resolution of tissue inflammation and promote the repair of refractory wounds. Ebid $e t a l^{21}$ observed the curative effect of HILT for the treatment of neuropathic foot ulcers in children with spina bifida. Compared with sham HILT in this previous study, the wound area and the total pressure sore state tool scores of the patients in the HILT group were more significantly decreased. Their study confirmed that HILT combined with standard wound care can decrease wound size and improve wound appearance by direct stimulation of wound cells and the immune regulatory system.

As shown in table 2, compared with the baseline, significant decreases in the BWAT and PUSH scores were observed at week 1-3 in both the treatment and control groups, except for the PUSH score in the control group at week 1 . These results showed that both standard wound care and HILT treatment could promote refractory wound repair and reduce scar formation. Furthermore, the BWAT scores of the patients in the treatment group were significantly improved at weeks 2 and 3 . At the same time, the PUSH scores of these patients were significantly lower than those in the control group at weeks 1, 2 and 3. These data indicated that HILT in combination with wound dressing was superior to conventional wound care for the treatment of chronic refractory wounds. The interaction of bio-objects with laser radiation depends on several factors such as wavelength, irradiation mode (continuous or pulse), pulse duration, pulse time interval, energy fluence, power output and irradiance. ${ }^{22}$ The treatment parameters of HILT used in the present study were a wavelength of $1064 \mathrm{~nm}$, power of $8 \mathrm{~W}$ and energy flow density of $80 \mathrm{~J} / \mathrm{cm}^{2}$. These parameters provided high energy density to ensure that more photonic energy effectively penetrated and reached the deeper target tissues while preventing skin overheating, resulting in a desired high level of multidirectional energy in a short time period. ${ }^{20}$ The intensity of a clinically available class IV therapy laser is up to $30 \times$ stronger than that of a class IIIb laser, and the therapeutic dose can be delivered to deep tissues in a short time period. In fact, with increasing

Table 3 Comparison of categorical subscores for wound size in the different study groups and at different time points

\section{Summary at different time points} median (minimum, maximum )

\begin{tabular}{lcccc} 
Group & Baseline & 1 week & 2 weeks & 3 weeks \\
\hline $\begin{array}{l}\text { All patients } \\
\text { BWAT (wound size) } \\
\text { Control }\end{array}$ & $2.0(1.0,4.0)$ & $2.0(1.0,4.0)$ & $2.0(1.0,4.0)$ & $1.0(0.0,3.0)$ \\
Treatment & $2.0(1.0,5.0)$ & $1.5(1.0,4.0)$ & $1.0(0.0,4.0)$ & $1.0(0.0,4.0)$ \\
\hline -value & 0.636 & 1.052 & 2.664 & 2.792 \\
p-value & 0.525 & 0.293 & $0.008^{* *}$ & $0.005^{* *}$ \\
PUSH (wound size) & $7.0(3.0,10.0)$ & $7.0(3.0,10.0)$ & $6.0(1.0,10.0)$ & $5.0(0.0,10.0)$ \\
Control & & & & \\
Treatment & $7.0(2.0,10.0)$ & $4.5(1.0,9.0)$ & $4.0(0.0,9.0)$ & $3.0(0.0,8.0)$ \\
\hline z-value & 0.686 & 2.379 & 3.170 & 2.825 \\
P-value & 0.493 & $0.017^{*}$ & $0.002^{* *}$ & $0.005^{* *}$ \\
\hline
\end{tabular}

${ }^{*} \mathrm{p}<0.05,{ }^{* *} \mathrm{p}<0.01$.

BWAT, Bates-Jensen Wound Assessment Tool; PUSH, Pressure Ulcer Scale for Healing Tool. 
power, HILT can penetrate $8-10 \mathrm{~cm}$ deeper into the body and might be an effective method for treating injuries that damage deep structures, such as bones, tendons, and nerves. ${ }^{23}$ The major biological effects of HILT include thermal, mechanical, electrical, photochemical and biostimulating effects. Previous studies have showed that irradiated cells could use the produced energy for cellular metabolism. ${ }^{24}$ Using a laser with a wavelength of $1064 \mathrm{~nm}$ provides the best absorption and penetration into tissue as its absorption by tissue chromophores, such as haemoglobin, melanin and water, is lower,; thereby enhancing the wound-healing process. ${ }^{25}$ The $1064 \mathrm{~nm}$ laser wavelength has other beneficial properties. It provides photobiomodulation by inducing increases in oxygen consumption, endogenous ATP synthesis and fission rate rhythm. ${ }^{26}$ Furthermore, this has been demonstrated to be the optimal wavelength to activate autophagy, which can promote cell metabolism and maintain normal physiological activity and homeostasis. ${ }^{27}$ Finally, it can promote the production of cytochrome oxidase and increase cellular or mitochondrial calcium uptake. ${ }^{28}$

The physiological effects of laser therapy include alterations in cell membrane permeability, with changes in intracellular calcium levels; increased cellular metabolism; altered DNA and RNA synthesis; fibroblast proliferation; activation of $\mathrm{T}$ lymphocytes, macrophages and mast cells; increased synthesis of endorphins and decreased synthesis of bradykinin. ${ }^{29}$ Hong et $a 2^{25}$ reported the biostimulatory effects of HILT on wound-healing process, demonstrating that HILT could promote fibroblast proliferation and result in significant increases in collagen synthesis, granulation tissue formation and extracellular matrix production. Furthermore, the anti-inflammatory effect of HILT can be achieved by the modulation of the inflammatory response, exudation, alteration and proliferation; stimulation of the readaptive reactions of the organism and inhibition of cyclooxygenases and lipoxygenases with modulation of prostaglandin and prostacyclin synthesis. ${ }^{30}$ All these mechanisms lead to improvements in oedema, healing process, local nutritional status of tissues and venous and lymphatic microcirculation. Finally, HILT can improve local blood circulation, blood vessel permeability and cell metabolism. ${ }^{31}$ Cellular biostimulation is realised via accelerated cellular metabolism by increasing the cellular mitotic index, which activates the repair process. Extracellular ion transport is further boosted by activating cell exchange. ${ }^{28}$

In our study, the BWAT score at week 1 was not significantly different between the two groups. This may be because the total score contains 13 individual items, namely, wound size, visible depth, wound edge, undermining and tunnelling processes, necrotic tissue type and amount, exudate type and amount, surrounding skin discolouration, peripheral tissue oedema, peripheral tissue induration, granulation tissue and epithelialisation. HILT is unlikely to have positive effects on each factor in a short period of time. Therefore, significant differences could only be seen from the second week of treatment.

\section{CONCLUSIONS}

HILT is effective for the treatment of chronic refractory wounds and should be considered for use with other therapeutic modalities. HILT can accelerate inflammatory absorption, increase collagen synthesis and tensile strength, shorten wound healing time and reduce wound size.

However, a major limitation of our study is that it included a variety of wounds of different aetiologies, pathologies and locations, which leads to confusion as to the best application of this technology. Due to the small number of patients with diabetic wounds and pressure injuries, we could not present subgroup analyses of the different wound types; furthermore, we could not elucidate difference in curative effects by treatment with HILT. Further research should categorise wounds into different groups based on different pathogeneses. In addition, more objective and accurate evaluation indices should be used to investigate the complex biological processes involved in wound healing.

\section{Author affiliations}

${ }^{1}$ Department of Rehabilitation Medicine, The Affiliated Jiangsu Shengze Hospital of Nanjing Medical University, Suzhou, Jiangsu, China

${ }^{2}$ Rehabilitation Medicine Center, The First Affiliated Hospital of Nanjing Medical University, Nanjing, Jiangsu, China

${ }^{3}$ Department of Outpatient Wound Care, The Affiliated Jiangsu Shengze Hospital of Nanjing Medical University, Suzhou, Jiangsu, China

Acknowledgements The authors thank Prof. Jinhui Ma and Dr. Huaide Qiu for the data analysis of this manuscript.

Contributors YS, ZY and $\mathrm{CH}$ designed the trial and wrote the manuscript. XS and $\mathrm{JL}$ facilitated patient recruitment and clinical data collection. QL, PS, MF, WL and XX performed the study procedures. All authors have read and approved the final manuscript.

Funding This work was supported by the Introduced Project of Suzhou Clinical Medical Expert Team (Number SZYJTD201725).

Competing interests None declared.

Patient and public involvement Patients and/or the public were involved in the design, or conduct, or reporting, or dissemination plans of this research. Refer to the Methods section for further details.

Patient consent for publication Not required.

Ethics approval This study was approved by the Ethics Committee of the First Affiliated Hospital of Nanjing Medical University (2019-SR-062) and was registered with the China Clinical Trial Registration Center (http://www.chictr.org.cn) under the number ChiCTR1900023157. All patients signed an informed consent form before they were randomly assigned into their respective groups. The original protocol for this study is available from URL: http://www.chictr.org.cn/edit.aspx?pid=38866\& $\mathrm{htm}=4$.

Provenance and peer review Not commissioned; externally peer reviewed.

Data availability statement Data are available upon reasonable request. Data may be obtained from a third party and are not publicly available. Data availability statement Data are available upon reasonable request. Some or all data generated or used during the study are available from the corresponding author by request. (Ying Shen; shenying_1981@hotmail.com).

Open access This is an open access article distributed in accordance with the Creative Commons Attribution Non Commercial (CC BY-NC 4.0) license, which permits others to distribute, remix, adapt, build upon this work noncommercially, and license their derivative works on different terms, provided the original work is properly cited, appropriate credit is given, any changes made indicated, and the use is non-commercial. See: http://creativecommons.org/ licenses/by-nc/4.0/. 
ORCID iD

Ying Shen http://orcid.org/0000-0001-8308-9562

\section{REFERENCES}

1 Tang J, Guan H, Dong W, et al. Application of compound polymyxin $B$ ointment in the treatment of chronic refractory wounds. Int J Low Extrem Wounds 2020:153473462094451.

2 Coalson E, Bishop E, Liu W, et al. Stem cell therapy for chronic skin wounds in the era of personalized medicine: from bench to bedside. Genes Dis 2019;6:342-58.

3 Griffiths $\mathrm{C}$, Howell RS, Boinpally $\mathrm{H}$, et al. Using advanced wound care and hyperbaric oxygen to manage wound complications following treatment of vulvovaginal carcinoma. Gynecol Oncol Rep 2018;24:90-3.

4 Dawood MS, Salman SD. Low level diode laser accelerates wound healing. Lasers Med Sci 2013;28:941-5.

5 Chaves MEdeA, Araújo ARde, Piancastelli ACC, et al. Effects of lowpower light therapy on wound healing: laser X led. An Bras Dermatol 2014;89:616-23.

6 Nilforoushzadeh MA, Kazemikhoo N, Mokmeli S, et al. An open-labe study of low-level laser therapy followed by autologous fibroblast transplantation for healing grade 3 burn wounds in diabetic patients. $J$ Lasers Med Sci 2019;10:S7-12.

7 Ezzati K, Laakso E-L, Salari A, et al. The beneficial effects of highintensity laser therapy and co-interventions on musculoskeletal pain management: a systematic review. J Lasers Med Sci 2020;11:81-90.

8 Abdelbasset WK, Nambi G, Alsubaie SF, et al. A randomized comparative study between high-intensity and low-level laser therapy in the treatment of chronic nonspecific low back pain. Evid Based Complement Alternat Med 2020;2020:1-6.

9 White PF, Zafereo J, Elvir-Lazo OL, et al. Treatment of drug-resistant fibromyalgia symptoms using high-intensity laser therapy: a casebased review. Rheumatol Int 2018;38:517-23.

10 Ebid AA, El-Sodany AM. Long-Term effect of pulsed high-intensity laser therapy in the treatment of post-mastectomy pain syndrome: a double blind, placebo-control, randomized study. Lasers Med Sci 2015;30:1747-55.

11 Thabet AAE-M, Mahran HG, Ebid AA, et al. Effect of pulsed high intensity laser therapy on delayed caesarean section healing in diabetic women. J Phys Ther Sci 2018;30:570-5.

12 Kaydok E, Ordahan B, Solum S, et al. Short-Term efficacy comparison of high-intensity and low-intensity laser therapy in the treatment of lateral epicondylitis: a randomized double-blind clinical study. Arch Rheumatol 2020;35:60-7.

13 Bates-Jensen BM, McCreath HE, Harputlu D, et al. Reliability of the Bates-Jensen wound assessment tool for pressure injury assessment: the pressure ulcer detection study. Wound Repair Regen 2019;27:386-95.

14 Sugihara F, Inoue N, Venkateswarathirukumara S. Ingestion of bioactive collagen hydrolysates enhanced pressure ulcer healing in a randomized double-blind placebo-controlled clinical study. Sci Rep 2018;8:11403.

15 Choi EPH, Chin WY, Wan EYF, et al. Evaluation of the internal and external responsiveness of the pressure ulcer scale for healing (push) tool for assessing acute and chronic wounds. J Adv Nurs 2016;72:1134-43.

16 Chan LN, Lai CKY. The effect of patient education with telephone follow-up on wound healing in adult patients with clean wounds: a randomized controlled trial. J Wound Ostomy Continence Nurs 2014;41:345-55.

17 Martin P, Nunan R. Cellular and molecular mechanisms of repair in acute and chronic wound healing. Br J Dermatol 2015;173:370-8.

18 Mosca RC, Ong AA, Albasha O, et al. Photobiomodulation therapy for wound care: a potent, noninvasive, Photoceutical approach. Adv Skin Wound Care 2019;32:157-67.

19 Alayat MSM, Aly THA, Elsayed AEM, et al. Efficacy of pulsed $\mathrm{Nd}$ :YAG laser in the treatment of patients with knee osteoarthritis: a randomized controlled trial. Lasers Med Sci 2017;32:503-11.

20 Thabet AAE-M, Elsodany AM, Battecha KH, et al. High-Intensity laser therapy versus pulsed electromagnetic field in the treatment of primary dysmenorrhea. J Phys Ther Sci 2017;29:1742-8.

21 Ebid AA, El-Kafy EMA, Alayat MSM. Effect of pulsed Nd:YAG laser in the treatment of neuropathic foot ulcers in children with spina bifida: a randomized controlled study. Photomed Laser Surg 2013;31:565-70.

22 Uba Al, Tabakoglu HO, Abdullahi UA, et al. Closure of skin incision by dual wavelength (980 and $1064 \mathrm{~nm}$ ) laser application. J Cosmet Laser Ther 2017;19:109-13.

23 Panton L, Simonavice E, Williams K, et al. Effects of class IV laser therapy on fibromyalgia impact and function in women with fibromyalgia. J Altern Complement Med 2013;19:445-52.

24 Ebid AA, Alhammad RM, Alhendi RT, et al. Immediate effect of pulsed high-intensity neodymium-doped yttrium aluminum garnet (Nd: YAG) laser on Staphylococcus aureus and Pseudomonas aeruginosa growth: an experimental study. J Phys Ther Sci 2019;31:925-30.

25 Hong SE, Hong MK, Kang SR, et al. Effects of neodymium-yttriumaluminum garnet (Nd:YAG) pulsed high-intensity laser therapy on full thickness wound healing in an experimental animal model. J Cosmet Laser Ther 2016;18:432-7.

26 Amaroli A, Benedicenti A, Ravera S, et al. Short-pulse neodymium:yttrium-aluminium garnet (Nd:YAG 1064nm) laser irradiation photobiomodulates mitochondria activity and cellular multiplication of Paramecium primaurelia (Protozoa). Eur J Protistol 2017;61:294-304.

27 Bostanciklioglu M, Demiryürek Şeniz, Cengiz B, et al. Assessment of the effect of laser irradiations at different wavelengths $(660,810,980$ and $1064 \mathrm{~nm}$ ) on autophagy in a rat model of mucositis. Lasers Med Sci 2015;30:1289-95.

28 Alayat MS, El-Sodany AM, Ebid AA, et al. Efficacy of high intensity laser therapy in the management of foot ulcers: a systematic review. $J$ Phys Ther Sci 2018;30:1341-5.

29 Karu TI, Kolyakov SF. Exact action spectra for cellular responses relevant to phototherapy. Photomed Laser Surg 2005;23:355-61.

30 Laser-Tissue Interactions - Fundamentals and Applications | Markolf Niemz | Springer. Available: https://www.springer.com/gp/book/ 9783662047170 [Accessed 10 Sep 2020].

31 Kul'chitskaya DB, Konchugova TV, Luk'yanova TV, et al. The substantiation for the application of high-intensity laser therapy for the treatment of the patients presenting with gonarthrosis. Vopr Kurortol Fizioter Lech Fiz Kult 2015;92:23-6. 